\title{
RELATIVIZAÇÃ̃ DA IMUNIDADE DE JURISDIÇÃO DOS ORGANISMOS INTERNACIONAIS FRENTE À VIOLAÇÃO AO DIREITO HUMANO FUNDAMENTAL DE ACESSO À JUSTIÇA ${ }^{1}{ }^{2}$
}

\section{RELATIVIZATION OF JURISDICTIONAL IMMUNITY OF INTERNATIONAL ORGANIZATIONS COMPARED TO VIOLATION OF THE FUNDAMENTAL HUMAN RIGHT OF ACCESS TO JUSTICE}

André Soares de Azevedo Branco Pós-graduado em Processo Civil e Direito Individual e Processual do Trabalho pela Faculdade de Direito de Vitória (FDV). Alunos especial do Mestrado em Direito Processual pela Universidade Federal do Espírito Santo (UFES), nos semestres 2018/01 e 2018/02. Graduado em direito pela Faculdade de Direito de Vitória (FDV). Advogado. Vitória/ES. E-mail: aabranco@gmail.com

RESUMO: Este artigo examina a questão da imunidade de jurisdição das organizações internacionais e sua importância para um sistema de proteção dessas instituições, dando ênfase ao conflito com o princípio do acesso à justiça e possibilidade, em decorrência dessa violação, da relativização da imunidade de jurisdição dessas organizações internacionais.

PALAVRA-CHAVE: Organizações Internacionais. Imunidade de jurisdição. Mecanismos alternativos de solução de disputas. Eficácia e adequação. Violação direito de acesso à justiça.

\footnotetext{
${ }^{1}$ Artigo recebido em 10/04/2019 e aprovado em 26/07/2019.

${ }^{2}$ Artigo produzido sob a orientação da Prof. Doutora Valesca Raizer Borges Moschen, como requisito para a aprovação na disciplina de Processo Civil Internacional Comparado do Programa de pós-graduação em Direito Processual da Universidade Federal do Espírito Santo.
} 
ABSTRACT: This article examines the question of jurisdiction immunities of international organizations and their importance for a system of protection of such institutions, emphasizing the conflict with the principle of access to justice and the possibility, as a result of this violation, of the relativization of the immunity of these international organizations.

KEYWORDS: International organizations. Jurisdictional immunity. Alternative dispute resolution mechanisms. Effectiveness and suitability. Violation of the right of access to justice.

SUMÁRIO: 1. Introdução; 2. Organizações internacionais; 3. Imunidade de jurisdição das organizações internacionais: fundamento e fontes jurídicas; 4. Direito fundamental de acesso à justiça; 5. Imunidade das organizações internacionais e violação do acesso à justiça; 6. Critérios de eficácia e adequação dos mecanismos alternativos de solução das disputas; 7. Experiência brasileira. 8. Conclusão; 9. Referências bibliográficas.

\section{INTRODUÇÃO}

As organizações internacionais são entidades recentes, idealizadas a partir da metade do século XIX, com o objetivo precípuo de reunir Estados Soberanos, assim, obtendo soluções comuns a todos eles.

Por não possuírem o elemento soberania, decorrência da inexistência de território próprio, tais entidades ficam sujeitas a ingerências de governos soberanos com o qual possuem relação.

Por essa razão, para se preservar e garantir sua independência para o exercício e realização de suas funções, mostrou-se necessária a criação de regras capazes de conceder a elas privilégios e imunidades, dentre as quais figura a imunidade de jurisdição.

Ocorre que, em determinado momento, aquelas regras criadas para garantir a independência funcional das organizações internacionais, acabaram por criar uma situação de injustiça, ao atingir um número cada vez maior de pessoas que ficaram impossibilitadas 
de buscar socorro junto ao Poder Judiciário, em virtude do benefício da imunidade de jurisdição.

O objetivo proposto neste artigo, portanto, é saber se existe alguma forma de violação ao princípio do acesso à justiça em decorrência dessas regras de imunidade de jurisdição das organizações internacionais. E ainda, se seria possível a relativização de tais regras em decorrência de uma suposta ofensa ao princípio do acesso à justiça.

\section{ORGANIZAÇÕES INTERNACIONAIS}

Precedendo à análise do problema proposto, qual seja, a correlação entre a questão da imunidade de jurisdição das organizações internacionais e a "suposta" violação do princípio da inafastabilidade da jurisdição (direito de acesso à justiça), mostra-se necessária, primeiramente, a definição do que são organizações internacionais.

Tal tarefa se justifica, uma vez que, segundo ensinam Fernando Guilhon de Castro e Tamires Hübner (2013, p. 110), o seu conceito não se encontra disposto em normas internacionais, mas sim, na doutrina especializada.

Neste sentido, em obra que trata dos limites da jurisdição brasileira, a Prof. Carmen Tiburcio (2016, p. 398) propõe o seguinte conceito de organização internacional. In verbis:

As organizações internacionais são definidas como entes criados por Estados, por meio de atos regidos pelo direito internacional e que têm personalidade jurídica própria. Podem também ser definidas como associações voluntárias de direito internacional, constituídas por ato internacional e disciplinadas nas relações entre as partes por normas de direito internacional, que possuem ordenamento jurídico interno próprio e são dotadas de órgãos e institutos próprios, por meio dos quais realizam as finalidades comuns de seus membros mediante funções particulares e o exercício de poderes que lhes foram conferidos. Ademais, podem desempenhar funções de natureza econômica, humanitária, comercial ou até mesmo política.

Edward Chukwuemeke Okeke (2018, p. 231), adotando a definição constante no projeto sobre responsabilidade das organizações internacionais elaborado pela International Law Commission da Organização das Nações Unidas no ano de 2011, apresenta a definição in verbis: 
Generally, "international organization" refers to an organization established by treaty or other legal instruments governed by international law and possessing its own international personality.

Geralmente, "organização internacional" refere-se a uma organização estabelecida por tratado ou outros instrumentos legais regidos pelo direito internacional e que possuem sua própria personalidade internacional.

Uma vez compreendido o conceito de organizações internacionais, necessário entender que elas, na forma moderna como atualmente existem, decorrem de um longo processo evolutivo, que segundo afirmam Silva, Souza, Oliveira e Tito (2007, p. 150/151), teve a sua origem ligada à necessidade de cooperação entre os Estados para a obtenção de soluções comuns que atendessem à totalidade das nações, como forma derivada e mais completa das conferências internacionais responsáveis pela celebração de tratados multilaterais.

Foi assim, segundo Okeke (2018, p. 235/236), que durante o século XIX começaram a surgir diversas organizações funcionais (também conhecidas por uniões públicas internacionais), com o objetivo proposto de coordenar assuntos considerados fundamentais para os governos nacionais, dentre os quais podemos elencar como as mais importantes: a Comissão criada para a administração dos rios europeus (1815), seguido da União Telegráfica Internacional (1865) e da União Postal Internacional (1874).

Mais tarde, no ano de 1920, com a assinatura do Tratado de Versalhes e a criação da Liga das Nações (posteriomente substituída pelas Nações Unidas no ano de 1945), essas organizações funcionais evoluíram para a forma como hoje conhecemos das organizações internacionais (fase moderna), com objetivos precípuos de promoção, preservação e proteção de interesses comuns dos Estados.

Contudo, para o melhor desempenho de suas atividades e realização de seus objetivos, mostra-se fundamental para essas organizações e seus funcionários a concessão de privilégios e imunidades, dentre os quais figura como de máxima importância o benefício da imunidade de jurisdição, tema tratado a seguir.

\section{IMUNIDADE DE JURISDIÇÃO DAS ORGANIZAÇÕES INTERNACIONAIS: FUNDAMENTO E FONTES JURÍDICAS}


Durante o processo de amadurecimento das organizações internacionais, iniciado na metade do século XIX, muito se discutiu sobre qual seria a fonte de inspiração deste tipo de imunidade, se espelhada na imunidade de jurisdição dos Estados ou na imunidade de jurisdição das missões diplomáticas. ${ }^{3}$

Diferentemente da imunidade de jurisdição dos Estados, fundada nos princípios do par in parem non habet e da não ingerência nos assuntos internos dos Estados ${ }^{4}$, e da imunidade de jurisdição das missões diplomáticas, baseada na representação do $\operatorname{Estado}^{5}$, a imunidade de jurisdição das organizações internacionais encontra fundamento diverso, no princípio da necessidade funcional.

Essa é a conclusão a que chega Lindén (2018, p. 19), ao expor precisamente em sua tese o fundamento das imunidades das organizações internacionais. In verbis:

While state immunity is based on the par in parem non habet imperium principle, international organization base their immunity on the principle of functional necessity. The doctrine of functional necessity has granted international organizations as much jurisdictional immunity as they need to exercise their functions in order to fulfil their intended purposes.

Enquanto a imunidade do Estado é baseada no princípio parem non habet imperium, a organização internacional baseia sua imunidade no princípio da necessidade funcional. A doutrina da necessidade funcional concedeu às organizações internacionais tanta imunidade jurisdicional quanto necessário para exercer suas funções a fim de cumprir seus propósitos pretendidos.

\footnotetext{
${ }^{3}$ A presente discussão mostra-se perfeitamente sintetizada na obra do prof. Guido Fernando Silva Soares (1984, p. 164): "Alguns autores, no capítulo das imunidades das organizações internacionais, insinuam, como Accioly, que as normas se inspiraram de certo modo, nas regras vigentes acerca dos privilégios e imunidades das missões diplomáticas ou das prerrogativas que gozam os Estados, uns em face dos outros. Outros, com apoio na jurisprudência norte-americana (caso Ranollo, que será examinado a seguir) afastam qualquer assimilação entre as imunidades diplomáticas tradicionais, concedidas aos diplomatas: "com efeito, estes não escapam absolutamente a qualquer jurisdição, pois, teoricamente, continuam submetidos às instâncias de seus Estados nacionais respectivos."

No mesmo sentido Cançado Trindade (2014, p. 478): "De todo modo, como se formou, ainda que de modo otimizado, um corpus juris sobre os privilégios e imunidades das organizações internacionais, não se mostrou necessário nem apropriado acudir a "analogias"com o regime jurídico das imunidades dos Estados e seus agentes."

${ }^{4}$ Carneiro (2016, p. 287): “A imunidade soberana assenta em dois princípios principais: o primeiro, expresso pela máxima par in parem non habet jurisdictionem, significa que "as pessoas jurídicas internacionais de igual posição não podem ver os seus litígios resolvidos pelos tribunais de uma delas"; o segundo princípio baseia-se na não ingerência nos assuntos internos dos outros Estados."

5 Tiburcio (2016, p. 377/378)
} 
É dizer quem, atualmente, as organizações internacionais não gozam mais de imunidade absoluta para o exercício de seus objetivos ${ }^{6}$, mas tão somente de uma imunidade funcionalmente limitada, relacionada ao exercício das funções necessárias ao desempenho dos seus objetivos previstos no seu tratado constitutivo, conforme se observa, por exemplo, no art. $105, \S 1^{\circ}$ da Carta das Nações Unidas ${ }^{7}$, e no art. 139 da Carta da Organização dos Estados Americanos ${ }^{8}$.

É como concluem Reinisch e Weber (2004, p. 63), ao fazerem um paralelo entre a visão tradicional da imunidade das organizações internacionais e sua limitação funcional. In verbis:

The traditional view seems to be that functional immunity necessarily leads to absolute immunity as a result of the functional personality concept of international organizations. As opposed to states, the international legal personality of international organizations is generally considered to be functionally limited. In other words, international organizations enjoy legal personality only to the extent required to perform their functions.

A visão tradicional parece ser que a imunidade funcional necessariamente leva à imunidade absoluta como resultado do conceito funcional pessoal das organizações internacionais. Ao contrário dos Estados, a personalidade jurídica internacional das organizações internacionais é geralmente considerada funcionalmente limitada. Em outras palavras, as organizações internacionais gozam de personalidade jurídica apenas na medida necessária para desempenhar suas funções.

Fixado o fundamento e os limites da imunidade de jurisdição das organizações internacionais, necessário é, ainda, tratar das suas fontes, que são os tratados internacionais

\footnotetext{
${ }^{6}$ Tal conclusão é bem exposta por Carmen Tiburcio (2016, p. 399/400): “assim, a imunidade era ampla, abrangendo atividades ligadas (ou não) aos objetivos da organização. A lógica imediata do benefício implica permitir que a organização exerça os seus objetivos funcionais sem qualquer interferência externa, o que poderia acontecer caso se admitisse que a organização fosse submetida ao Judiciário do país sede, levada por particulares ou até mesmo pelo Estado membro, gerando a situação de o Estado se configurar ao mesmo tempo em parte e julgado do litígio.(...)

Nessa linha, a regra geral para as organizações internacionais sempre foi a imunidade absoluta, salvo raríssimas excessões. Dessa forma, nas relações entre funcionários (locais ou não) com a organização, bem como para as vítimas de ilícitos por ela causados ou ainda nas relações puramente comerciais envolvendo a organização sempre prevaleceu a imunidade. Houve época em que se fazia necessária essa proteção com vistas a permitir o exercício dos objetivos do ente internacional, mas críticas têm sido feitas à imunidade absoluta desses entes, pois essa proteção muitas vezes leva à denegação de justiça."

${ }^{7}$ A Organização gozará, no território de cada um dos seus Membros, dos privilégios e imunidades necesários à realização do seu propósito.

${ }^{8}$ A Organização dos Estados Americanos gozará, no território de cada um dos seus Membros, de capacidade jurídica, dos privilégios e das imunidades que forem necessárias para o exercício das suas funções e a realização de seus propósitos.
} 
Rio de Janeiro. Ano 13. Volume 20. Número 3. Setembro a Dezembro de 2019

Periódico Quadrimestral da Pós-Graduação Stricto Sensu em Direito Processual da UERJ

Patrono: José Carlos Barbosa Moreira (in mem.). ISSN 1982-7636. pp. 33-50

www.redp.uerj.br

e documentos constitutivos das próprias organizações, mas não os costumes

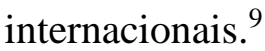

\section{DIREITO FUNDAMENTAL DE ACESSO À JUSTIÇA}

O direito de acesso à justiça, como direito fundamental de levar uma reclamação perante um tribunal para julgá-lo de forma justa e equitativa, com o respeito ao devido processo legal, encontra-se previsto em diversos instrumentos internacionais de proteção e promoção dos direitos humanos, dentre os quais: na Declaração Universal de Direitos Humanos $^{10}$, na Declaração Americana dos Direitos e Deveres do Homem ${ }^{11}$, na Convenção Americana sobre Direitos Humanos ${ }^{12}$, no Pacto Internacional sobre Direitos Civis e Políticos ${ }^{13}$, e na Convenção Européia de Direitos Humanos ${ }^{14}$.

Neste sentido, é a lição de Campeão, Moschen e Gimenez (2018, p. 158/159). In verbis:

En el ámbito del derecho internacional, la garantía de acceso a proceso justo y equitayivo pasó a representar una preocupación recurrenteen los instrumentos internacionales de protección y promoción de los derechos fundamentales en el transcurso del tiempo.

(...)

El principio del acceso a la justicia, sobre todo en su acepción que trasciende la esfera de localidad, presupone la noción de proceso justo y

\footnotetext{
${ }^{9}$ Castro e Hübner (2013, p. 113).

${ }^{10}$ Art. 10. Todo ser humano tem direito, em plena igualdade, a uma audiência justa e pública por parte de um tribunal independente e imparcial, para decidir sobre seus direitos e deveres ou do fundamento de qualquer acusação criminal contra ele.

11 Art. 18. Toda pessoa pode recorrer aos tribunais para fazer respeitar os seus direitos. Deve poder contar, outrossim, com processo simples e breve, mediante o qual a justiça a proteja contra atos de autoridade que violem, em seu prejuízo, qualquer dos direitos fundamentais consagrados constitucionalmente.

12 Art. 8. Toda pessoa tem direito a ser ouvida, com as devidas garantias e dentro de um prazo razoável, por um juiz ou tribunal competente, independente e imparcial, estabelecido anteriormente por lei, na apuração de qualquer acusação penal formulada contra ela, ou para que se determinem seus direitos ou obrigações de natureza civil, trabalhista, fiscal ou de qualquer outra natureza.

${ }^{13}$ Art. 14. 1. Todas as pessoas são iguais perante os tribunais e as cortes de justiça. Toda pessoa terá o direito de ser ouvida publicamente e com devidas garantias por um tribunal competente, independente e imparcial, estabelecido por lei, na apuração de qualquer acusação de caráter penal formulada contra ela ou na determinação de seus direitos e obrigações de caráter civil. (...)

${ }^{14}$ Art. 6. 1. Qualquer pessoa tem direito a que a sua causa seja examinada, equitativa e publicamente, num prazo razoável por um tribunal independente e imparcial, estabelecido pela lei, o qual decidirá, quer sobre a determinação dos seus direitos e obrigações de carácter civil, quer sobre o fundamento de qualquer acusação em matéria penal dirigida contra ela. (...)
} 
equitativo, que se materializa por medio de la observancia de los vectores del debido proceso legal, efectividad, isonomía, contradicción, amplia defensa y amplia de su duración razonable.

No âmbito do direito internacional, a garantia de acesso a processos justos e equitativos passou a representar uma preocupação recorrente nos instrumentos internacionais de proteção e promoção dos direitos fundamentais ao longo do tempo.

(...)

$\mathrm{O}$ princípio do acesso à justiça, especialmente em seu significado que transcende a esfera da localidade, pressupõe a noção de um processo justo e equitativo, que se materializa através da observância dos vetores do devido processo legal, efetividade, isonomia, contradição, ampla defesa e sua duração razoável.

Desta forma, uma vez considerado o conteúdo do direito fundamental de acesso à justiça, existiria, no caso de acolhimento da preliminar de imunidade de jurisdição das organizações internacionais, a violação daquele direito fundamental?

É o que se propõe responder a seguir.

\section{IMUNIDADE DAS ORGANIZAÇÕES INTERNACIONAIS E VIOLAÇÃO DO ACESSO À JUSTIÇA}

Pois bem. Estabelecidas as premissas anteriores, (i) de que as organizações internacionais somente possuem imunidade de jurisdição em relação aos atos praticados no exercício dos seus objetivos e (ii) de que o direito de acesso à justiça (direito a ser ouvido por um tribunal independente e imparcial) é um direito humano fundamental, questiona-se se o benefício da imunidade de jurisdição das organizações internacionais violaria de alguma forma o direito do requerente de acessar um tribunal ${ }^{15}$.

Como regra, têm-se entendido que a imunidade de jurisdição das organizações internacionais, desde que existentes outros meios para a solução das controvérsias postas, não violaria o direito de acesso à justiça. ${ }^{16}$

\footnotetext{
${ }^{15}$ Neste ponto precisa é a lição de Leandro de Oliveira Moll (2011, p. 133), ao apontar o aspecto da exigência de um tribunal acessível como aspecto da garantia de acesso à justiça: "No bojo da ampla garantia judicial que tais normas traduzem (acesso à justiça), interessa-nos especificamente um aspecto primordial, a saber, a exigência de um tribunal acessível, que é informada pelo que podemos chamar de princípio da não denegação de Justiça ou de acesso a um tribunal (accès au juge; acess to a court), conforme se queira utilizar uma construção negativa ou positiva."

${ }^{16}$ Registre-se opinião dissonante da Suprema Corte do Canadá no julgamento Amaratunga v. Northwest Atlantic Fisheries Organization: "The absence of a dispute resolution mechanism or of an internal review
} 
Neste sentido, a Corte Europeia de Direitos Humanos, quando teve a oportunidade de analisar a questão nos casos Waite and Kennedy v. German ${ }^{17}$ e Beer and Regan v. German $^{18}$, decidiu de forma unânime que a decisão alemã que aplicou a imunidade das organizações internacionais não violava o direito dos requerentes de acesso à justiça, na medida em que foi garantido a eles o acesso a outros meios independentes de resolução do conflito.

Logo, segundo Okeke (2018, p. 330), é possível afirmar que, atualmente, a jurisprudência da Corte Européia de Direitos Humanos não reconhece na imunidade das organizações internacionais violação ao direito de acesso à justiça, quando estas oferecerem outros mecanismos independentes de resolução de disputas. In verbis:

Under the EctHR jurisprudence, it can safely infer that as long as an international organization provides an independent dispute resolution mechanism, its jurisdictional immunity would be respect by national courts.

De acordo com a jurisprudência da Corte Europeia de Direitos Humanos, pode-se inferir com segurança que, enquanto uma organização internacional fornecer mecanismo independente de resolução de disputas, sua imunidade jurisdicional será respeitada pelos tribunais nacionais.

process is not, in and of itself, determinative of wheter [an international organization] is entitled to immunity."

A ausência de um mecanismo de resolução de litígios ou de um processo interno de revisão não é, por si só, determinante para o fato de [uma organização internacional] ter direito a imunidade.

${ }^{17}$ Caso $n^{\circ}$ 26083/94, da Corte Europeia de Direitos Humanos. "57. In view of all these circumstances, the Court finds that, in giving effect to the immunity from jurisdiction of ESA on the basis of section 20(2) of the Courts Act, the German courts did not exceed their margin of appreciation. Taking into account in particular the alternative means of legal process avaiable to the applicants, it cannot be said the limitation on theis access to the German courts with regard to ESA impaired the essence of their "right to a court" or was disproportionate for the purposes of Article $6 \S 1$ of the Convention."

57. Tendo em conta todas estas circustâncias, o Tribunal considera que, ao dar efeito à imunidade de jurisdição da Agência Européia Espacial com base no artigo 20(2) da Lei dos Tribunais, os tribunais alemães não excederam a sua margem de apreciação. Tendo em conta, em especial, os meios alternativos de processo jurídico à disposição dos recorrentes, não se pode afirmar que a limitação do seu acesso aos Tribunais alemães em relação à AEE prejudicou a essência do seu "direito a um tribunal"ou foi desproporcionada para os fins do art. $6 \S 1$ da Convenção."

18 Caso $n^{\circ}$ 28934/95, da Corte Europeia de Direitos Humanos: “(...) Taking into account in particular the alternative means of legal process avaiable to the applicants, it cannot be said the limitation on theis access to the German courts with regard to ESA impaired the essence of their "right to a court" or was disproportionate for the purposes of Article $6 \S 1$ of the Convention."

“(...) Tendo em conta, em especial, os meios alternativos de processo jurídico à disposição dos recorrentes, não se pode afirmar que a limitação do seu acesso aos Tribunais alemães em relação à AEE prejudicou a essência do seu "direito a um tribunal"ou foi desproporcionada para os fins do art. $6 \S 1$ da Convenção." 
Portanto, conforme dito acima, nos termos das decisões paradigmáticas proferidas pela Corte Europeia de Direitos Humanos, que determinaram o caminho da jurisprudência da Corte, tornou-se regra que a concessão de imunidade às organizações internacionais não viola o direito de acesso à justiça, desde que existentes outros mecanismos alternativos, independentes e eficientes de solução dos conflitos.

Contudo, tal regra não é absoluta, estabelecendo clara afronta ao princípio do acesso à justiça naqueles casos em que os meios alternativos postos à disposição para a solução do conflito não se mostrarem suficientemente eficazes/adequados, o que leva à necessidade de rejeição da preliminar de imunidade arguida.

É o que aponta Okeke (2018, p. 330), ao citar decisões da Corte de Cassação da Bélgica $^{19}$ e França ${ }^{20}$ que indeferiram o pedido de imunidade de jurisdição das organizações internacionais, por entenderem deficientes os mecanismos de resolução de conflitos postos a disposição dos indivíduos demandantes. In verbis:

In the wake of Waite and Kennedy, Belgian and French courts have declined to give effect to the jurisdictional immunity of international organizations in three cases where they found the dispute resolution mechanism in those organizations deficient.

Na esteira de Waite and Kennedy, os tribunais belga e francês se recusaram a dar efeito à imunidade jurisdicional das organizações internacionais em três casos em que consideraram deficiente o mecanismo de resolução de disputas naquelas organizações.

Neste sentido, mostra-se plenamente admissível a rejeição da preliminar de imunidade das organizações internacionais pela violação do direito de acesso à justiça do indivíduo, quando os mecanismos de solução de conflitos disponibilizados forem considerados ineficazes/inadequados, restando necessário saber, nestes casos, quais seriam os critérios de adequação/eficácia desses mecanismos.

\section{CRITÉRIOS DE EFICÁCIA E ADEQUAÇÃO DOS MECANISMOS ALTERNATIVOS DE SOLUÇÃO DAS DISPUTAS}

\footnotetext{
${ }^{19}$ Lutchmaya v. General Secretariat of the African, Caribbean and Pacific Group of States (ACP) e Siedler v. Western European Union.
} 
Rio de Janeiro. Ano 13. Volume 20. Número 3. Setembro a Dezembro de 2019

Periódico Quadrimestral da Pós-Graduação Stricto Sensu em Direito Processual da UERJ

Patrono: José Carlos Barbosa Moreira (in mem.). ISSN 1982-7636. pp. 33-50

www.redp.uerj.br

Conforme já tratado nos tópicos anteriores, adotou-se como regra geral pelos tribunais nacionais e internacionais que a imunidade de jurisdição das organizações internacionais, quando disponibilizados meios alternativos eficazes/adequados de solução dos conflitos, não viola o direito do demandante de acesso à justiça.

De toda sorte, referida regra não é absoluta, admitindo a sua relativização, com a consequente rejeição da preliminar de imunidade de jurisdição e continuidade da ação, quando os mecanismos de resolução de disputas disponibilizados pela organização ao indivíduo demandante forem considerados deficientes.

Portanto, para o objetivo pretendido de justificar a rejeição da preliminar de imunidade de jurisdição, e consequente processamento da ação perante cortes nacionais em decorrência da violação do direito de acesso à justiça, imperioso se faz definir quais são os critérios de eficácia/adequação desses mecanismos alternativos de solução de disputas disponibilizados pelas organizações internacionais.

Neste sentido, com fundamento na lição de Reinisch e Weber (2004, p. 102/109), pode-se elencar como critérios de eficácia/adequação dos mecanismos alternativos de solução de disputas (i) a necessidade de independência dos juízes do "tribunal administrativo", (ii) o problema da localização e da língua adotada no procedimento, e (iii) a observância das garantias processuais e de publicidade das decisões proferidas nos referidos órgãos.

Com relação à necessidade de independência dos juízes do mecanismo de resolução utilizado pela organização internacional, é necessário que os julgadores sejam qualificados $^{21}$ e que exista transparência quanto à indicação dos seus membros, para assim evitar qualquer tipo de pressão da organização internacional sobre eles, garantindo, desta forma, a independência e a imparcialidade exigida no seu julgamento. ${ }^{22}$

\footnotetext{
${ }^{20}$ Degboe v. African Development Bank.

${ }^{21}$ Reinisch e Weber (2004, p. 103): "In those circumstances, not only the chairman but also the other members should be persons of a recognized high moral character, who must possess the qualifications required for an appointment to judicial office."

Nessas circunstâncias, não apenas o presidente, mas também os outros membros devem ser pessoas de alto caráter moral reconhecido, devendo possuir as qualificações necessárias para uma nomeação para um cargo judicial.

${ }^{22}$ Reinisch e Weber (2004, p. 104): "In cases where the tenure of office of judges is quite short, where their service is subject to re-appointment and where the nomination of candidates remais under the control of the defendent organization, serius questions arise regarding the independence and impartiality of an appointed judge or member of an internal appeals board."
} 
Quanto ao requisito geográfico e linguístico, seja pela distância do local de residência do indivíduo demandante frente à localização do órgão julgador, seja pela língua adotada no procedimento administrativo de solução do conflito, caso não exista alguma forma de ajuda ao indivíduo demandante (com o auxílio de tecnologia para resolução do problema da distância ou fornecimento de intérprete ou advogado dativo para as questões relacionadas ao direito discutido e idioma utilizado), estará criando uma barreira intransponível ao exercício do seu direito de demandar em face da organização internacional, impedindo o seu direito de acesso à justiça, na medida em que não terá ele condições financeiras de arcar com os custos envolvidos no procedimento. ${ }^{23}$

Por último, é ainda necessário que sejam observadas todas as garantias processuais, dentre as quais figuram a necessidade de um julgamento justo e da publicidade das decisões proferidas, como forma de conhecer/avaliar os posicionamentos dos tribunais administrativos.

Por isso, com o devido respeito às opiniões divergentes, entendo que uma vez ausente qualquer dos requisitos acima destacados, resta claramente violado o direito de acesso à justiça do indivíduo, cuja consequência deve ser a relativização da imunidade de jurisdição das organizações internacionais, e consequente rejeição da preliminar arguida e processamento da ação judicial na corte nacional.

\section{EXPERIÊNCIA BRASILEIRA}

No Brasil, o tratamento jurisprudencial dado ao problema da imunidade de jurisdição dos organismos internacionais nem sempre foi uniforme, o que vem sendo corrigido em anos recentes.

Contudo, o caminho percorrido para essa uniformização, até o presente momento, vem sendo realizado pura e simplesmente sob a perspectiva da legalidade do

Nos casos em que o mandato dos juízes é bastante curto, onde o serviço está sujeito a uma nova nomeação e onde a nomeação dos candidatos permanece sob o controle da organização defensora, surgem sérios questinamento relativos à independência e imparcialidade de um juiz nomeado ou membro de um conselho interno de recursos.

${ }^{23}$ Reinisch e Weber (2004, p. 106): "Persons other than staff members will not necessarily possess the qualifications, for example linguistic ability, financial independence or the particular legal standing (...)."

As pessoas que não sejam membros da organização internacional não terão necessariamente as qualificações, por exemplo, capacidade linguística, independência financeira ou a posição jurídica específica. 
reconhecimento dessa imunidade jurisdicional, sem, contudo, atentar-se para a possível violação ao direito de aceso à justiça do demandante.

A título ilustrativo, o Tribunal Superior do Trabalho, no ano de 2007, ao julgar o Recurso de Revista $\mathrm{n}^{\circ}$ 19500-73.2004.5.10.0013, determinou que a imunidade de jurisdição dos organismos internacionais se restringia aos atos de império, afastando-a nas demais hipóteses, e admitindo, por óbvio, o prosseguimento de ações ajuizadas em face de organizações internacionais. In verbis:

RECURSO DE REVISTA - ORGANISMO INTERNACIONAL IMUNIDADE DE JURISDIÇÃO . Esta Corte tem entendido que os entes de direito público externo não possuem imunidade absoluta de jurisdição. A imunidade de jurisdição dos organismos internacionais se restringe aos atos de império, dentre os quais não se inclui os relacionados à legislação trabalhista. Efetivamente, são atos de gestão os concernentes às relações de trabalho, como os em debate na presente ação, em que o Reclamante pleiteia o reconhecimento do vínculo de emprego e o direito a parcelas decorrentes do contrato de trabalho, não havendo que se falar, portanto, em imunidade de jurisdição. Precedentes do TST. Recurso de Revista conhecido e provido"

Por outro lado, o Supremo Tribunal Federal apresentava posicionando em sentido contrário, a favor do reconhecimento da imunidade de jurisdição absoluta dos organismo internacionais, o que fez com que a Seção de Dissídios Individuais do Tribunal Superior do Trabalho alterasse a posição original daquela corte, e editasse Orientação Jurisprudencial $\mathrm{n}^{\mathrm{o}} 416$, estabelecendo que "as organizações ou organismos internacionais gozam de imunidade absoluta de jurisdição quando amparados por norma internacional incorporada ao ordenamento jurídico brasileiro, não se lhes aplicando a regra do Direito Consuetudinário relativa à natureza dos atos praticados. Excepcionalmente, prevalecerá a jurisdição brasileira na hipótese de renúncia expressa à cláusula de imunidade jurisdicional."

Mais recentemente, o Supremo Tribunal Federal, ao julgar conjuntamente os Recursos Extraordinários $\mathrm{n}^{\circ} 578.543$ e $\mathrm{n}^{\circ}$ 597.368, deu provimento aos mesmos, confirmando e reconhecendo a imunidade de jurisdição e execução dos organismos internacionais. In verbis: 


\begin{abstract}
Ementa: DIREITO INTERNACIONAL PÚBLICO. DIREITO CONSTITUCIONAL. IMUNIDADE DE JURISDIÇÃO. ORGANIZAÇÃO DAS NAÇÕES UNIDAS (ONU). PROGRAMA DAS NAÇÕES UNIDAS PARA O DESENVOLVIMENTO (ONU/PNUD). RECLAMAÇÃO TRABALHISTA. CONVENÇÃO SOBRE PRIVILÉGIOS E IMUNIDADES DAS NAÇÕES UNIDAS (DECRETO 27.784/1950). APLICAÇÃO. 1. Segundo estabelece a "Convenção sobre Privilégios e Imunidades das Nações Unidas", promulgada no Brasil pelo Decreto 27.784, de 16 de fevereiro de 1950, "A Organização das Nações Unidas, seus bens e haveres, qualquer que seja seu detentor, gozarão de imunidade de jurisdição, salvo na medida em que a Organização a ela tiver renunciado em determinado caso. Fica, todavia, entendido que a renúncia não pode compreender medidas executivas". 2. Esse preceito normativo, que no direito interno tem natureza equivalente a das leis ordinárias, aplica-se também às demandas de natureza trabalhista. 3. Recurso extraordinário provido.
\end{abstract}

Neste julgamento, a maioria dos ministros seguiu o voto da Ministra Ellen Gracie, que se posicionou a favor da absoluta imunidade de jurisdição dos organismos internacionais, desde que amparados por norma incorporada ao direito nacional, pois violaria obrigações internacionais assumidas pelo Brasil. Ademais, ainda destacaram que eventuais demandantes já se encontravam cientes, desde o início, da sua relação com a organização que eventuais litígios não seriam submetidos à jurisdição brasileira.

Destaca-se no referido acórdão, contudo, o Voto-vista proferido pela Ministra Cármen Lúcia, que no sentido proposto no presente trabalho, abriu divergência, reconhecendo a imunidade da organização internacional, mas manifestando grande preocupação com a criação de um limbo jurídico capaz de negar ao cidadão brasileiro o direito fundamental de acesso à justiça. São as suas palavras:

Preocupa a criação de um limbo jurídico, no qual prevaleça a anomia e o destrato normativo a garantir direitos dos trabalhadores. Quem trabalha tem direitos e para a sua garantia, em caso de descumprimento, há de haver um órgão judicial pronto a lhe responder, seja quem for $\mathrm{o}$ empregador.

(...)

Aliás, é exatamente o direito ao acesso a um órgão judicial independente um dos direitos fundamentais constantes da Declaração dos Direitos do Homem e do Cidadão, tida como ponto nuclear da existência da ONU. 
Já no ano de 2017, com o julgamento do Recurso Extraordinário n ${ }^{\circ} 1.034 .840$, que teve repercussão geral reconhecida, o Supremo Tribunal Federal novamente se deparou com a questão da imunidade de jurisdição dos organismos internacionais, oportunidade em que reafirmou a jurisprudência dominante sobre a matéria, nos termos propostos pelo Relator Ministro Luiz Fux. In verbis:

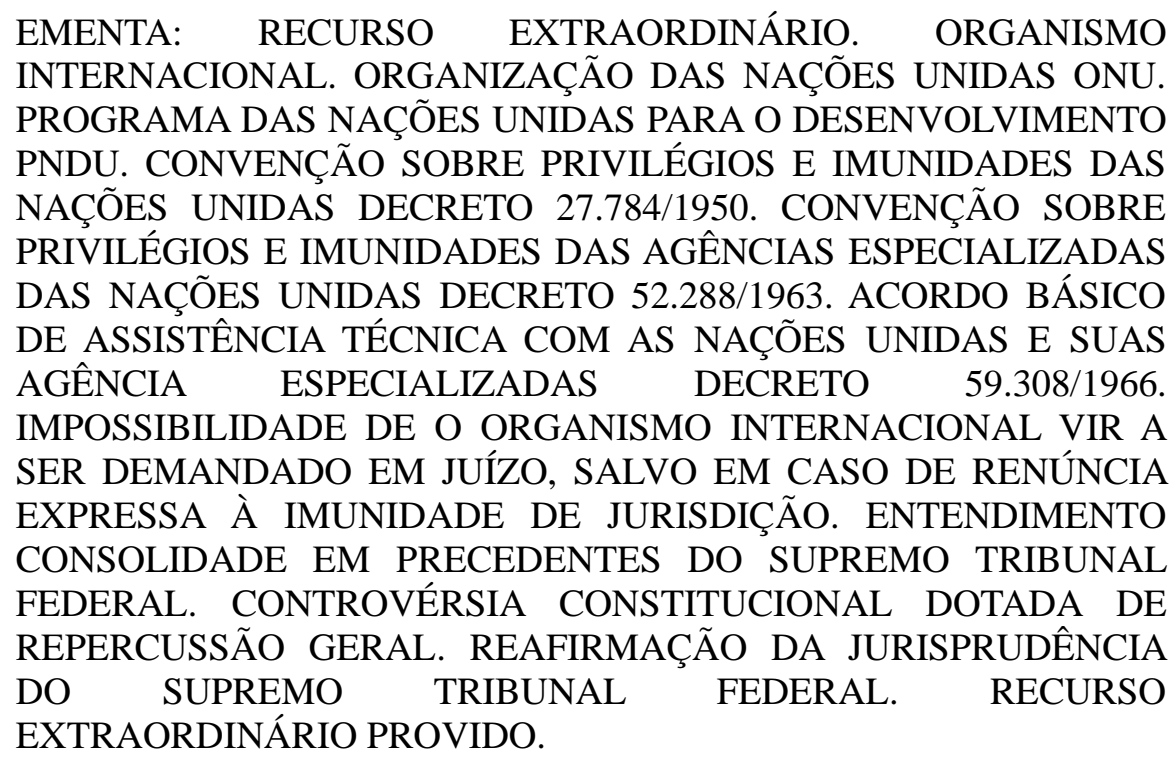

Na ocasião, foi fixada tese de repercussão geral, na qual "o organismo internacional que tenha garantida a imunidade de jurisdição em tratado firmado pelo Brasil e internalizado na ordem jurídica brasileira não pode ser demandado em juízo, salvo em caso de renúncia expressa a essa imunidade", para ser aplicada pelo tribunal aos demais recursos referente ao mesmo assunto.

\section{CONCLUSÃO}

Diante de todo o exposto, é possível concluir que a imunidade de jurisdição das organizações internacionais, quando prevista em tratado ou ato constitutivo internalizado no Brasil alguma espécie de mecanismo de solução da controvérsia distinto do Poder Judiciário, não configuram violação ao direito de acesso à justiça. 
Tal desfecho se dá pelo fato de que essa determinação não implica em qualquer tipo de impunidade das organizações internacionais, tão somente determinando que o julgamento seja realizado em foro mais adequado que o poder judiciário nacional.

Da mesma forma, pela regra acima destacada, a ausência deste foro alternativo para a resolução da controvérsia apresentada em face das organizações internacionais é suficiente para configurar a lesão ao direito de acesso à justiça, criando hipótese de relativização do benefício da sua imunidade.

Contudo, defendo que além da existência de um foro alternativo para a solução das controvérsias apresentadas, é necessário que este seja adequado e eficaz para o julgamento da questão, com o atendimento de garantias processuais mínimas, como independência/ imparcialidade dos julgadores e publicidade das decisões proferidas, além da mitigação dos problemas geográficos e linguísticos decorrentes da localização do mecanismo de resolução, sob pena, conforme alertado pela Ministra Cármen Lúcia, de criar um limbo jurídico no qual seja violado o direito de acesso à justiça do cidadão brasileiro, oportunidade em que caberia a relativização da imunidade de jurisdição dos organismos internacionais.

Neste sentido, com o devido respeito, acredito que o Supremo Tribunal Federal, no julgamento dos Recursos Extraordinário $\mathrm{n}^{\circ} 578.543, \mathrm{n}^{\circ} 597.368$ e $\mathrm{n}^{\circ} 1.034 .840$, tenha dito menos do que deveria, adotando uma solução simplista de reconhecimento da imunidade absoluta de jurisdição dos organismos internacionais, sem que fosse considerada a real consequência deste reconhecimento nos casos de reconhecimento/ineficácia dos meios de solução de conflitos previstos na norma incorporada, bem como a eventual possibilidade, decorrente da violação do direito fundamental constitucional do cidadão de acesso à justiça, de relativização da imunidade de jurisdição dos organismos internacionais.

\section{REFERÊNCIAS}

CAETANO, Fernanda Araújo Kallás e. A imunidade de jurisdição das organizações internacionais face ao direito de acesso à justiça. Revista de direito internacional. Brasília, v. 13, n. 3, 2016, p. 390-403. 
CAMPEÃO, Paula Soares; JIMENEZ, Martha Lucia Olivar; MOSCHEN, Valesca Raizer Borges. Entre la cruz y la espada: El derecho del acceso a la justicia y las inmunidades de jurisdicción de los estados. Revista de direito brasileira. São Paulo, vol. $19, \mathrm{n}^{\circ} 08$, p. $155 / 159,2018$;

CANÇADO TRINDADE, Antônio Augusto. Direito das organizações internacionais. 6. ed. Belo Horizonte: Del Rey, 2014.

CARNEIRO, Elisa Resende Bueno da F. Ximenes. Direitos humanos, violações a normas de jus cogens e imunidade do estado: estudo do caso Alemanha versus Italia (CIJ). Rio de Janeiro: Editora Lumen Juris, 2016;

CASTRO, Fernando Guilhon de; HÜBNER, Tamires. Imunidade absoluta de jurisdição dos organismos internacionais e a violação aos direitos humanos (trabalhistas): comentários à OJ 416 do TST. Meritum, Revista de direito da universidade FUMEC. Belo Horizonte, v. 08, n. 1, 2013, p. 99-141.

LINDÉN, Johan. Immunity of international organizations and the right of acess to justice for individuals. 2018. Dissertação (Mestrado em direito internacional público). Uppsala University.

MOLL, Leandro de Oliveira. Imunidades internacionais: Tribunais nacionais ante a realidade das organizações internacionais. Brasília: Fundação Alexandre de Gusmão, 2011.

OKEKE, Edward Chukwuemeke. Jurisdictional immunities of states and international organizations. New York: Oxford University Press, 2018.

SILVA, Edvan Carneiro da; SOUSA, James Alberto Vitorino de; OLIVEIRA, João Resende Almeida; TITO, Maíra. Origem, características e classificação das organizações internacionais. Revista do Mestrado em direito da Universidade Católica de Brasília. Brasília, v. 1, n. 2, 2007, p. 147-162.

SOARES, Guido Fernando da Silva. Das imunidades de jurisdição e de execução. Rio de Janeiro: Forense, 1984.

TIBURCIO, Carmen. Extensão e limites da jurisdição brasileira: competência internacional e imunidade de jurisdição. Salvador: JusPODIVM, 2016.

WEBER, Ulf Andreas; REINISCH, August. In the shadow of Waite and Kennedy - The jurisdictional immunity of international organizations, the individual's right of access 
Rio de Janeiro. Ano 13. Volume 20. Número 3. Setembro a Dezembro de 2019

Periódico Quadrimestral da Pós-Graduação Stricto Sensu em Direito Processual da UERJ

Patrono: José Carlos Barbosa Moreira (in mem.). ISSN 1982-7636. pp. 33-50

www.redp.uerj.br

to the courts and administrative tribunal as alternative means of dispute settlement.

International organizations law review. 1, 2004, p. 59-110. 